\title{
Awake intubation increases intracranial pressure without affecting cerebral blood flow velocity in infants
}

Tracheal intubation is frequently required in neonatal anaesthetic practice. Awake intubation is one method of securing the airway and in certain circumstances, for many anaesthetists, can be prejerable to intubation following induction of anaesthesia. Previous studies have inferred that the elevation in anterior fontanelle pressure observed during tracheal intubation in neonates was caused by an increase in cerebral blood flow although it was never measured. In this study, direct methods were used to observe changes in the cerebral circulation. Thirteen neonates, ASA I to III (E), aged from l to 34 days of age were studied. Patients were randomized to receive either tracheal intubation awake or following induction of anaesthesia with thiopentone $5 \mathrm{mg} \cdot \mathrm{kg}^{-1}$ and succinylcholine $2 \mathrm{mg} \cdot \mathrm{kg}^{-1}$. Heart rate, systolic arterial blood pressure, anterior fontanelle pressure, cerebral blood flow velocity (using transcranial Doppler sonography) and oxygen saturation were recorded at the following intervals: baseline (not crying), after intravenous atropine $0.02 \mathrm{mg} \cdot \mathrm{kg}^{-1}$, during laryngoscopy, inmediately afier insertion of the endotracheal tube, one and five minutes later. The use of atropine masked the cardiovascular responses to intubation. Whereas the change in anterior fontanelle pressure from baseline was different between the groups $(P<0.05)$. the cerebral blood flow velocity variables were not. The rise in anterior fontanelle pressure seen in the awake group may

\section{Key words}

ANAESTHESIA: paediatric;

BRAIN: blood flow, intracranial pressure; INTUBATION, TRACHEAL: technique.

From the Department of Anaesthesia, The Hospital for Sick Children, University of Toronto, Toronto, Ontario, M5G IX8 Canada. Presented in part at the Annual Meeting of the American Society of Anesthesiologists, October 1992, New Orleans, LO.

Address correspondence to: Dr. B. Bissonnette, Department of Anaesthesia, The Hospital For Sick Children, 555 University Avenue, Toronto, Ontario, Canada, M5G 1X8. TEL: 416-8136466; FAX: 416-813-7543.

Accepted for publication 3rd December, 1993. be attributed to a reduction of the venous outflow from the cranium thereby increasing cerebral blood volume and subsequently the intracranial pressure.

En anesthésie néonatale, lintubation endotrachéale est souvent nécessaire. Lintubation éveillée est utilisée pour le maintien de la perméabilité des voies respiratoires et dans certaines circonstances, plusieurs anesthésistes la préferent à linubation sous anesthésie générale. Auparavant des études ont conclu que laugmentation de la pression de la fontanelle antérieure observée pendant limtubation endotrachéale du nouveau-né était due à ume augmentation du débit sanguin cérébral bien qu'on ne lait jamais mesurée. Dans cette étude, des méthodes directes sont utilisées pour l'observation des changements de la circulation cérébrale. Treize nouveaux-nés, ASA I à III (E), âgés de 1 à 34 jours font partie de létude. Ils sont répartis au hasard pour subir une intubation endotrachéale soit éveillés, soit sous anesthésie au thiopentone $5 \mathrm{mg} \cdot \mathrm{kg}^{-1}$ et à la succinylcholine $2 \mathrm{mg} \cdot \mathrm{kg}^{-1}$. La fréquence cardiaque, la tension antérielle systolique, la pression de la fontanelle antérieure, la vélocité du débit sanguin cérébral (par sonographie intracrânienne au Dop. pler) et la saturation en oxygène sont enregistrées aux intervals suivants: ligne de base (sans pleurs de lenfant), après atropine $\dot{N} 0,02 \mathrm{mg} \cdot \mathrm{kg}^{-1}$, pendant la laryngoscopie, immédiatement après linsertion du tube endotrachéal et une et cing minutes plus tard. Lutilisation de latropine masque la réponse cardiovasculaire à lintubation. Alors que les variations de la pression de la fontanelle antérieure mesurées différent de la ligne de base diffêrent entre les groupes $(P<0,05)$, les variables de la vélocité du débit sanguin cérébral ne diffêrent pas. Lélévation de la pression de la fontanelle antérieure constatée chez le groupe éveillé est possiblement attribuable d̀ une baisse du drainage veineux intracrânien avec augmentation consécutive du volume sanguin cérébral et subséquemment de la pression intracrânienne.

Tracheal intubation is a necessary part of the anaesthetic management of many paediatric patients in the operating room. In adults, the responses to laryngoscopy and tra- 
cheal intubation have been well documented. ${ }^{1,2}$ The increases in intracranial pressure (ICP) associated with manipulation of the airway have been attributed to alterations in the blood pressure and heart rate. Tracheal intubation in the neonate may be performed while awake patient or following induction of anaesthesia and the use of a muscle relaxant. Awake intubation is an accepted technique at this age and may, in certain circumstances, be the method of choice. ${ }^{3}$ However, some clinicians consider it to be an unnecessary haemodynamic stress. ${ }^{4}$

In paediatric patients, changes in ICP have been observed most easily in the neonate where the anterior fontanelle provides a "window" for monitoring pressure changes within the cranium. ${ }^{5}$ Several studies have shown that the anterior fontanelle pressure (AFP) increases during tracheal intubation. ${ }^{1,6}$ The increases in AFP are greater in the awake than in the anaesthetized infants. Several theories have been advanced to account for this including hypoxaemia and the change in systolic blood pressure. However, the changes in cerebral blood flow velocity during tracheal intubation have not been investigated.

Transcranial Doppler sonography (TCD) is a noninvasive, direct and sensitive monitor that measures the cerebral blood flow velocity (CBFV) in any of the basal arteries. ${ }^{7,8}$ When it is applied to the temporal area of the head, it allows continuous recording from the middle cerebral artery (MCA). The MCA is the largest artery of all basal arteries constituting the Circle of Willis and is responsible for $70 \%$ of the blood flow to the ipsilateral hemisphere. ${ }^{9}$ The advantage of recording CBFV from the MCA is that the Ml segment of the MCA presents an angle less than $20^{\circ}$ when compared to the temporal window which limits the effect on the doppler shift at less than $6 \%$ (cosine of the angle).

Therefore, this study was designed to determine the effect of changes in systolic arterial blood pressure, heart rate and CBFV variables on AFP during tracheal intubation performed in awake or anaesthetised neonates.

\section{Methods}

Following approval from the Human Subjects Review Committee and after informed written parental consent was obtained, 14 patients aged one to 42 days were studied. All patients were scheduled to undergo elective or emergency surgery requiring the placement of an endotracheal tube. Exclusion criteria included the presence of known intracranial, cardiovascular or laryngeal pathology. Finally, patients with a gestational age $<32$ wk were excluded owing to technological limitations.

All patients were fasted, unpremedicated and randomly allocated to receive either awake intubation or thipentone $5 \mathrm{mg} \cdot \mathrm{kg}^{-1}$ and succinylcholine $2 \mathrm{mg} \cdot \mathrm{kg}^{-1}$ to facilitate tracheal intubation. To avoid the haemodynamic effects of the placement of an intravenous catheter while awake, all patients arrived at the operating room with an intravenous access already established. All patients were placed supine with the head supported in a head ring. Routine monitoring devices (ECG, blood pressure cuff, radial Doppler probe, oxygen saturation monitor and temperature probe) were applied. Blood pressure was taken manually using a sphygmomanometer and a Doppler probe overlying the radial artery. Heart rate (HR) was recorded from the ECG. The TCD monitor (Transpect, Medasonics, Fremont CA.) was placed over the right temporal region to record flow in the M1 segment of the right middle cerebral artery. At each study period a file from the TCD was recorded representing eight seconds of Doppler flow velocity profiles from the M1 segment. The Bunegin-Albin fontanelle monitor (Cook Critical Care, Stouffville, Ont.) was placed over the anterior fontanelle. ${ }^{10}$ The hemispheric dome was calibrated on a flat surface while attached by a fluid-filled connecting tube to a calibrated transducer prior to placement over the anterior fontanelle. The transducer and fontanometer were at the same level during recordings and the firm outer rim of the fontanometer was sited such that it made good contact with the osseous vault, thus leaving the membrane in contact with the whole of the fontanelle. Recordings of mean AFP were made continuously with each event being marked on the printout.

Following baseline observations all patients received pre-oxygenation for three minutes and atropine 0.02 $\mathrm{mg} \cdot \mathrm{kg}^{-1} \dot{i}$. In the awake intubation group, once an increase in heart rate was seen after atropine, laryngoscopy and tracheal intubation were performed. Similarly, in the group receiving intravenous anaesthesia and after the rise in heart rate, thiopentone $5 \mathrm{mg} \cdot \mathrm{kg}^{-1}$ and succinylcholine $2 \mathrm{mg} \cdot \mathrm{kg}^{-1}$ were given. Laryngoscopy and tracheal intubation were carried out in the usual manner.

With the endotracheal tube correctly positioned all patients received $70 \%$ nitrous oxide in oxygen and halothane 1 MAC, age-corrected, for the remainder of the study. Intermittent positive-pressure ventilation was instituted at this time.

Observations were made at the following intervals: (0) At rest. (1) After $\dot{i}$ atropine. (2) At laryngoscopy. (3) Immediately after intubation. (4) One minute after intubation. (5) Five minutes after intubation. The variables recorded were heart rate, systolic blood pressure, oxygen saturation and mean AFP. A CBFV profile was also recorded. All measurements were made by an investigator (CM) not involved in the anaesthetic management of the infant. The analysis of each TCD file was done by the other investigator (BB) who was unaware of the method 
TABLE Demographic, haemodynamic and cerebral blood flow variables at rest

\begin{tabular}{lccl}
\hline Variables & $\begin{array}{l}\text { Anaesthetised } \\
(n=6)\end{array}$ & $\begin{array}{l}\text { Awake } \\
(n=7)\end{array}$ & $P<0.05$ \\
\hline $\begin{array}{l}\text { Demographics } \\
\text { Age (days) }\end{array}$ & $16 \pm 15$ & $9 \pm 12$ & NS \\
Weight (kg) & $4.0 \pm 1$ & $3.0 \pm 1$ & NS \\
Sex (M:F) & $4: 2$ & $3: 4$ & \\
Haemodynamics & & & \\
HR (bpm) & $159 \pm 30$ & $141 \pm 16$ & NS \\
SABP (mmHg) & $87 \pm 26$ & $73 \pm 27$ & NS \\
AFP (mmHg) & $8.2 \pm 3.8$ & $4.6 \pm 2.2$ & NS \\
CBFV (cm sec $\left.^{-1}\right)$ & & & \\
Vs & $54.4 \pm 22.4$ & $61.6 \pm 25.1$ & NS \\
Vm & $33.1 \pm 13.7$ & $38.8 \pm 17.6$ & NS \\
Vd & $17.2 \pm 7.9$ & $21.6 \pm 14.1$ & NS \\
RI+ & $0.68 \pm 0.11$ & $0.67 \pm 0.16$ & NS \\
\hline
\end{tabular}

Data expressed as mean $\pm \mathrm{SD}$.

HR, heart rate; SABP, systolic arterial blood pressure; AFP, anterior fontanelle pressure; CBFV, cerebral blood flow velocity; Vs, systolic peak flow velocity; $\mathrm{Vm}$, mean flow velocity; $\mathrm{Vd}$, diastolic peak flow velocity; RI+, cerebrovascular resistance; NS, non-significant.

of tracheal intubation. Each file represents eight seconds of recording from which a minimum of three cycles were used to evaluate the CBFV variables such as the peak systolic velocity $(\mathrm{Vs})$ and the mean velocity $(\mathrm{Vm})$. The mean cerebral blood flow velocity $(\mathrm{Vm})$ was calculated from the area under the curve of each three to five strokes which was multiplied by the elapsed time and averaged.

\section{Statistical analysis}

Data with parametric values are expressed as mean \pm $\mathrm{SD}$. Based on a previous human neonate study ${ }^{5}$ a power analysis was performed and for a power of 0.80 , an alpha value of 0.05 and a beta value of 0.20 , the calculated number of patients to reject the null hypothesis was seven per group. Demographic data and the differences between the groups for AFP and CBFV variables at each stage were compared using Student's unpaired $t$ test. Within group differences were compared using the repeatedmeasure analysis and the Student-Newman-Keuls test for multiple comparisons. A $P<0.05$ was accepted for statistical significance.

\section{Results}

Data on 13 patients are reported. One patient was excluded due to incomplete data at laryngoscopy. There were no differences between the groups with respect to age, weight or in regard to baseline $H R$, systolic BP, AFP or CBFV variables (Table).

There were no differences between the groups with respect to heart rate changes after administration of at-

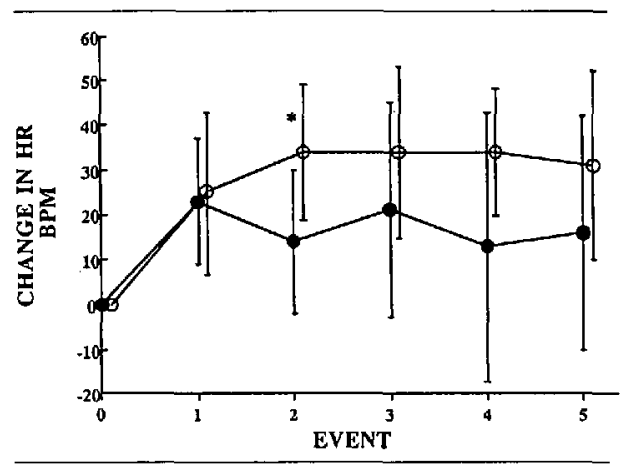

FIGURE I The changes in heart rate (HR) from bascline values in the awake $(O)$ and anaesthetised groups (O). Only at laryngoscopy Event 2 - does the difference between the groups reach significance $\left({ }^{*} P\right.$ $<0.05$ ). Events: $0=$ baseline, $1=$ post-atropine, $2=$ laryngoscopy, 3 $=$ post-intubation, $4=1$ minute post-intubation, $5=5$ minutes postintubation.

ropine intravenous. However, after Event 1, this increase in heart rate was sustained in the awake group whereas it decreased in the anaesthetised group for the duration of the study period. At laryngoscopy the change in heart rate recorded between the groups was different with the awake group being higher $(P<0.05)$ (Figure 1). There were no differences between the groups with respect to changes in systolic arterial blood pressure at any of the study intervals (Figure 2). However, both groups showed increases in $\mathrm{BP}$ at the time of laryngoscopy $(P<0.05)$ (Figure 2).

There were no decreases in oxygen saturation in either group at any of the study intervals. The lowest oxygen saturation recorded was $96 \%$.

There was an increase in AFP from resting values at the time of laryngoscopy in the awake group $(P<0.05)$ (Figure 3 ) which returned to baseline following intubation and induction of anaesthesia. Anterior fontanelle pressure did not increase significantly in the asleep group although the rise in AFP from baseline represented a $254 \%$ change in the awake patients compared to a $44 \%$ change in the asleep group.

There were no differences in the values of CBFV between the groups or within the groups. The Vm, Vs and Vd at the time of laryngoscopy were not different from baseline in either group. The Vm is represented in Figure 4.

There were no complications observed in this study.

\section{Discussion}

This study has shown that there is an increase in AFP during awake intubation in the neonate but this elevation 


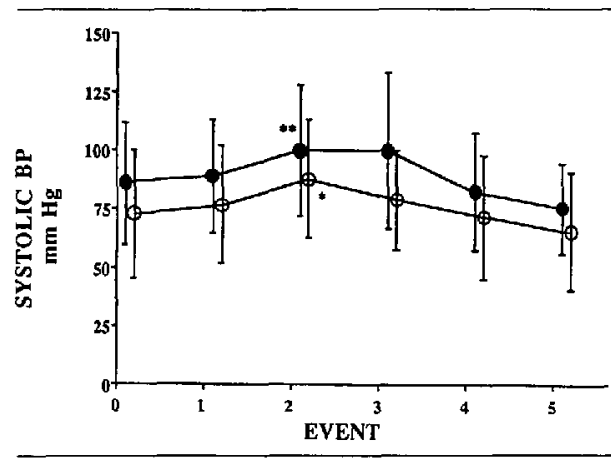

FIGURE 2 The changes in systolic blood pressure (BP) for the awake $(O)$ and the anaesthetised groups $(O)$ are shown. Both groups show an increase in systolic BP at the time of laryngoscopy - Event 2 when compared with baseline and post-atropine values $(* P<0.001$ awake, $* * P<0.00$ l anaesthetised). Events: $0=$ baseline, $1=$ postatropine, $2=$ laryngoscopy, $3=$ post-intubation, $4=1$ minute postintubation, $5=5$ minutes post-intubation.

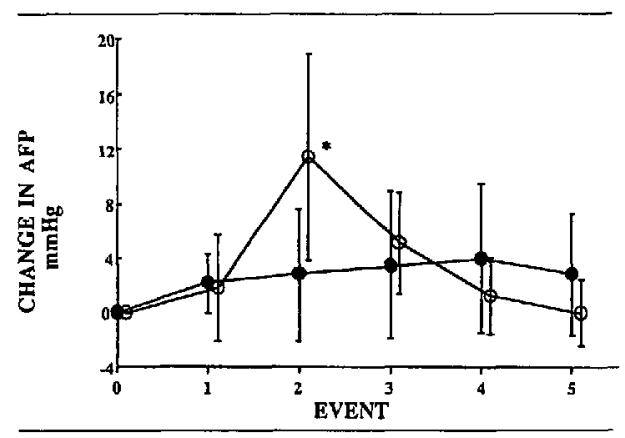

FIGURE 3 Change in atnerior fontanelle pressure (AFP) from baseline in the awake $(O)$ and anaesthetised groups $(\Theta)\left({ }^{*} P<0.05\right)$. Events: $0=$ baseline, $1=$ post-atropine, $2=$ laryngoscopy, $3=$ postintubation, $4=1$ minute post-intubation, $5=5$ minutes postintubation.

is not associated with a change in cerebral blood flow velocity ( $\mathrm{CBFV}$ ). $\mathrm{A}$ rapid sequence induction of anaesthesia using thiopentone followed by succinylcholine and tracheal intubation produces a smaller increase in anterior fontanelle pressure which also cannot be explained by changes in CBFV.

The elevation in AFP is taken as an indirect measure of an increase in intracranial pressure (ICP). ${ }^{10,11}$ Changes in AFP are suspected to be detrimental to an infant at risk from intraventricular haemorrhage., ${ }^{5,12}$ Studies have suggested that the acute rise in AFP is likely to be the

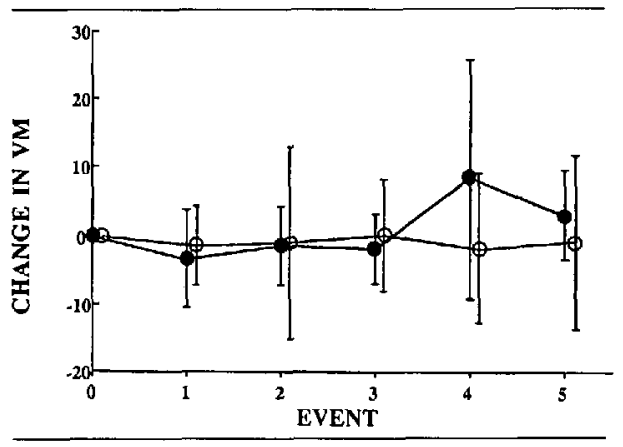

FIGURE 4 Changes in the mean cerebral blood flow velocity (Vm) in the awake $(O)$ and the anaesthetised $(\odot)$ groups. Events: $0=$ baseline, $1=$ post-atropine, 2 = laryngoscopy, $3=$ post-intubation, 4 $=1$ minute post-intubation, $5=5$ minutes post-intubation.

result of a change in cerebral haemodynamics, ${ }^{5}$ notably the changes in perfusion pressure at the time of laryngoscopy and intubation. However, no investigators have objectively demonstrated this contention. Kelly et al. ${ }^{1}$ suggested that venous obstruction during awake intubation was the prime cause of an increase in ICP and that transcranial Doppler sonography might detect these changes.

Transcranial Doppler sonography (TCD) is capable of detecting changes in flow velocity in the middle cerebral artery ${ }^{13}$ and thus could be expected to detect changes in cerebral blood flow velocity during laryngoscopy and endotracheal intubation if a change in cerebrovascular haemodynamic accounts for the rise in AFP. Normal paediatric values have been determined ${ }^{14}$ and it has been used successfully to detect the alteration of CBFV variables secondary to changes in carbon dioxide levels in children during anaesthesia. ${ }^{8}$

The cardiovascular responses to laryngoscopy and tracheal intubation are well documented, both in adults ${ }^{15}$ and neonates. ${ }^{5}$ Many techniques have been advocated to prevent the associated increase in ICP but control of one haemodynamic variable such as blood pressure does not necessarily control the other, although attenuation of the changes does occur. ${ }^{16}$ Therefore, this implies that blood pressure is not directly linked to ICP. The moderating factor could be the inherent autoregulatory ability of the cerebral circulation.

The use of atropine before tracheal intubation is standand practice in many institutions because either awake intubation or the use of succinylcholine is associated with the risk of bradycardia. Both of our study groups showed an identical increase in heart rate following its administration, but only in the awake group was this rise sustained for the remainder of the study period. It confirms 
that the constant increase in HR was due to the sympathetic stimulation triggered by the laryngoscopy technique. ${ }^{17}$ In the anaesthetized group the heart rate decreased after administration of the induction drugs and subsequently with laryngoscopy. The change in heart rate from baseline at laryngoscopy was different from the awake group. This may be the result of the myocardial depressant action of thiopentone combined with the vagotonic effect of succinylcholine. However, this alone would not account for the difference in AFP between the groups since the changes in systolic arterial blood pressure were identical in the two groups throughout the study period.

There are several technical considerations that merit comment. The accurate measurement of anterior fontanelle pressure with the Bunegin-Albin fontanometer relies on correct alignment of the pliable membrane over the fontanelle and for the outer rigid rim to lie on the adjacent osseous vault. If external pressure is applied to the monitor during this time a false reading of AFP is made. This is minimized by carefully positioning the infant and the device. Secondly, mean AFP recordings rather than peak pressures were taken to minimize any artifacts from movement of the infant during the study period.

Systolic arterial blood pressure was indicated by the return of Doppler sounds following manual inflation of the cuff at each study interval. In an awake and struggling infant this was more difficult than in the anaesthetized infant. However, the changes in systolic BP are similar in both groups and correspond with previous findings, so this error is judged to be small. Heart rate was recorded from the ECG. Oxygen saturation was more difficult to record due to interference from movement of the infant during the study period. However, no child was noted to have a saturation of $<96 \%$ at any of the intervals.

The TCD probe is applied with a small adhesive sticker to the temporal region. Loose application or movement of the probe during the study led to one child being excluded due to the poor quality of the TCD files recorded. Despite the increase in systolic arterial blood pressure there was no corresponding change in the CBFV variables of $\mathrm{Vs}$ and $\mathrm{Vd}$ in either group. However, the data were expressed in terms of mean flow velocity because this index is the least dependent upon systemic factors such as heart rate, contractility and total peripheral resistance. ${ }^{18}$ Furthermore, mean flow velocity has a higher correlation with cerebral blood flow than does the peak systolic or diastolic flow velocity. Finally, it reduces the interindividual variability observed with the other two parameters and it allows a more sensitive detection of changes in cerebral perfusion. ${ }^{19}$

In the awake group it could be argued that cerebral autoregulation is preserved and acts to minimize the change in blood flow due to the increase in blood pressure. Also in the awake group, following intubation, anaesthesia was induced with nitrous oxide in $70 \%$ oxygen and $1 \mathrm{MAC}$ halothane. Onset of anaesthesia was therefore slower which may account for the small change in CBFV seen during the study period.

It is known that certain medication used in anaesthesia can inhibit cerebral autoregulation which would lead to an increase in Vs and Vm. In the anaesthetised group this change in Vm did not occur until one minute after intubation. This delay could be explained by the utilisation of a "rapid sequence induction" technique, which ensures that intubation occurs shortly after the injection of thiopentone and succinylcholine. Thiopentone does not affect cerebral autoregulation but increases cerebrovascular resistance and reduces cerebral blood flow. ${ }^{20}$ Thus changes in $V_{s}$ and $V m$ are not seen until thiopentone redistribution has begun which correspond to more than one minute after intubation or two minutes after induction of anaesthesia. Two cerebral actions of thiopentone may be used to explain the observation in the anaesthetised group: firstly, it has a depressant effect on metabolic requirement for oxygen. If autoregulation is intact, this effect would reduce cerebral blood flow, cerebral blood volume and intracranial pressure. ${ }^{21}$ Secondly, the myocardial depressant effect may have contributed to reduce the increase in blood pressure. The overall effect would be a decrease in CBFV variables at the time of laryngoscopy in the anaesthetised group and not the observed identical change in the awake group. From this we conclude that cerebral autoregulation remained intact in the anaesthetised group at the time of laryngoscopy.

Laryngoscopy distorts the anatomy of the pharynx and upper airway during the visualization of the larynx and vocal cords. Stretching of the pharynx initiates sympathetic reflexes causing the cardiovascular responses to laryngoscopy. ${ }^{5}$ In the vigorous and awake infant, the muscular efforts to resist laryngoscopy and the attempt to cry are accompanied by an increase in intrathoracic pressure and consequently a reduction in venous return. Furthermore, distortion of the pharynx may cause physical obstruction to the drainage of blood from the brain causing venous hypertension within the cranium. Based on the pressure-volume index $\left(P V I=\Delta V / \log 10\left(P_{P} / P_{O}\right)\right)$ where $\Delta V$ is the volume of the fluid bolus, $P_{P}$ is the peak ICP after bolus injection, $P_{O}$ is the baseline ICP, the increase in volume required to raise the intracranial pressure by a factor 10 in infants is only $8-10 \mathrm{ml} \mathrm{com-}$ pared with $25 \mathrm{ml}$ in adults. ${ }^{22}$ Therefore, the consequences of these factors result in cerebral venous congestion with subsequent increase in anterior fontanelle pressure above resting levels. This would account for a rapid and shortlived increase in AFP. This mathematical expression dem- 
onstrates that even a slight obstruction of venous return can easily cause a significant increase in ICP. It is important to remember that the presence of open fontanelles and sutures is not a protective mechanism against an acute increase in ICP in infants. This anatomical distortion accompanied by raised intrathoracic pressure during attempts to cry would account for the rise in AFP above resting levels. With the anaesthetised group only anatomical factors are present to account for the moderate rise in AFP.

The TCD monitors the arterial blood flow input to the cerebral circulation; for changes on the venous side of the system to affect arterial inflow characteristics, the obstruction would have to be substantial and prolonged. Although laryngoscopy is a considerable stimulus it is neither prolonged nor does it completely obstruct venous outflow. Thus, for TCD to distinguish the small differences in CBFV variables between the groups a larger number of neonates needs to be studied.

In conclusion, anterior fontanelle pressure increases during awake intubation in the neonate. Although there were corresponding changes in heart rate and blood pressure in both anaesthetised and awake intubated groups the cerebral blood flow velocity in basal cerebral arteries did not change. It is suggested that obstruction to venous outflow by distortion of the anatomy of the great veins of the neck and raised intra-thoracic pressure during laryngoscopy are the cause of the rise in AFP and explains the differences between the groups.

\section{Acknowledgements}

We are grateful to Medasonic Inc, Fremont, CA for providing the TCD monitor and to Cook Critical Care, Stouffville, Ont. for the anterior fontanelle pressure monitoring device.

\section{References}

1 Kelly $M A$, Finer $N N$. Nasotracheal intubation in the neonate: physiologic responses and effects of atropine and pancuronium. J Paediatr 1984; 105: 303-9.

2 Moorthy SS, Greenspan CD, Dierdof SF, Sprague D. Cerebral blood flow increases and femoral blood flow decreases during laryngoscopy and tracheal intubation. Anesthesiology 1992; 77: A73.

3 Motoyama E. Endotracheal intubation. In: Motoyama EK, Davis PJ (Eds.). Smith's Anesthesia for Infants and Children. Sth ed. St-Louis: CV Mosby Co., 1990.

4 Bissonnette B, Sulinan PJ. Pyloric stenosis. Can J Anaesth 1991; 38: 668-76.

5 Friesen $R H$, Honda AT, Thieme RE. Changes in anterior fontanelle pressure in pre-term neonates during tracheal intubation. Anesth Analg 1987; 66: 874-8.

6 Stow PJ, McLeod ME, Burrows FA, Creighton RE.
Anterior fontanelle pressure responses to tracheal intubation in the awake and anaesthetized infant. $\mathrm{Br} \mathrm{J}$ Anaesth 1988; 60: 167-70.

7 Aaslid $R$, Markwalder $T M$, Nornes $H$. Noninvasive transcranial Doppler ultrasound recording of flow velocity in basal cerebral arteries. J Neurosurg 1982; 57: 769-74.

8 Pilato MA, Bissonnette B, Lerman J. Transcranial

Doppler: response of cerebral blood-flow velocity to carbon dioxide in anaesthetized children. Can J Anaesth 1991; 38: $37-42$.

9 Carpenter $M$, Sutin J. Human Neuroanatomy. 8th ed. Baltimore: Williams \& Wilkins Inc, 1983.

10 Bunegin $L$, Albin MS, Rauschhuber $R$, Marin AE. Intracranial pressure measurement from the anterior fontanelle utilizing a pneumoelectronic switch. Neurosurgery 1987; 20: 726-31.

11 Myerberg DZ, York C, Chaplin ER, Gregory GA. Comparison of noninvasive and direct measurements of intracranial pressure. Pediatrics 1980; 65: 473-6.

12 McDonald MM, Kloops BL, Johnson $M L$, et al. Timing and antecedents of intracranial hemorrhage in the newborn. Pediatrics 1984; 74: 32-6.

13 Markwalder TM, Grolimund P, Seiler RW, Roth F, Aaslid $R$. Dependency of blood flow velocity in the middle cerebral artery on end-tidal carbon dioxide partial pressure - a transcranial ultrasound Doppler study. J Cereb Blood Flow Metab 1984; 4: 368-72.

14 Bode $H$, Wais $U$. Age dependence of flow velocities in basal cerebral arteries. Arch Dis Child 1988; 63: 606-11.

15 Stoelting $R K$. Circulatory changes during direct laryngoscopy and tracheal intubation: influence of duration of laryngoscopy with or without prior lidocaine. Anesthesiology 1977 ; 47: 381-4.

16 Unni VKN, Johnston RA, Young HSA, McBride RJ. Prevention of intracranial hypertension during laryngoscopy and endotracheal intubation: use of a second dose of thiopentone. Br J Anaesth 1984; 56: 1219-23.

17 Bedford $R$, Winn H, Tyson G, Park $T$, Jane J. Lidocaine prevents increased ICP after endotracheal intubation. $m$ : Shulman K, Marmarou A, Miller JD, Becker DP, Hochwald GM, Brock M (Eds.). Intracranial Pressure IV, New York: Springer-Verlag 1980; 595-8.

18 Aaslid $R$. The Doppler principle applied to measurement of blood flow velocity in cerebral arteries. $I n$ : Aaslid $\mathrm{R}$ (Ed.). Transcranial Doppler Sonography, New York: Springer-Verlag, 1986: 22-38.

19 Hennerici $M$, Rautenberg W, Sitzer G, Schwartz A. Transcranial Doppler ultrasound for the assessment of intracranial arterial flow velocity - Part 1. Examination technique and normal values. Surg Neurol 1987; 27 : 439-48.

20 Pierce EC Jr, Lambertson CJ, Deutsch S, et al. Cerebral circulation and metabolism during thiopental anesthesia 
and hyperventilation in man. J Clin Invest 1962; 41 :

1664-71.

21 Donegan JH, Traystman RJ, Koehler RC, Jones $M D J r$. Rogers $M C$. Cerebrovascular hypoxic and autoregulator responses during reduced brain metabolism. Am J Physiol 1985; 249: H42I-6.

22 Shapiro K, Marmarou A. Mechanisms of intracranial hypertension in children, In: McLaurin RL, Venes J, Schut L et al. (Eds.). Pediatric Neurosurgery, Philadelphia: W.B.

Saunders, 1989; 338-46. 